\title{
El Buen Pastor y la Monarquía Católica en la segunda mitad del siglo XVII
}

\author{
IVÁN SÁNCHEZ LLANES*
}

\section{The Good Sherpherd and the Spanish Monarchy in the second middle of the XVII ${ }^{\text {th }}$ century}

\begin{abstract}
RESUMEN
En los siglos XVII y XVIII hay muchas maneras en las que se conceptualiza la relación entre el rey y la comunidad de vasallos, cada una de las cuales muestra algunos aspectos particulares de la teoría

y metodología de la praxis del poder político. En este artículo, vamos a explorar la imagen del «Buen pastor» en la monarquía católica en la segunda mitad del siglo XVII y los modos en que apunta una nueva percepción de los deberes y obligaciones que vinculan al rey y su reino.

PALABRAS CLAVE:

Buen Pastor, amor, disciplina, segunda mitad siglo XVII.

ABSTRACT

In the XVI and XVII centuries, there are several ways in which the relationship between the king and the community of the vassals is conceptualized, everyone of them showing some particular aspects of the theoretical and methodological praxis of the political power. In this article, we are going to explore the image of the "Good shepherd" in the Catholic monarchy in the second half of the XVII century and the ways in which it points out a new perception of the duties and obligations that links the king and its kingdom.

\section{KEYWORDS:}

Good shepherd, love, discipline, second half of the XVII century.

* Universidad Autónoma de Madrid. El presente artículo es el resultado y continuación del Proyecto de Investigación, Un ideal de gobierno: discurso pastoral en época de Carlos II, presentado en la Universidad Autónoma de Madrid para la adquisición de la suficiencia investigadora en diciembre de 2009. Quisiera agradecer las valiosas orientaciones y sugerencias realizadas por el director del mismo, el Dr. Antonio Álvarez-Ossorio, así como mi gratitud a los miembros del tribunal que juzga mi trabajo, los doctóres José Maria Iñurritegui Rodríguez y Julen Viejo Yharrassarry. iv-sanch@ hotmail.es
\end{abstract}


A la altura de 1638 parecía tener cabida en la Corte de la Monarquía Católica un interrogante nada trivial y escasamente superficial en torno a una «questión principal», que se fundaba sobre los derivados de una intensidad amorosa, la cual alcanzaba una profundidad que devenía «conclusión política». En esencia lo que se discutía era una cuestión de grado, es decir, quién debía amar con mayor vehemencia, «el Príncipe a los vassallos, o los vassallos al Príncipe»1. Ahora, por lo tanto, ya no se trataba de penetrar las formas políticas de un ordo amoris ${ }^{2}$, como dispositivo regulador de la necesaria habitabilidad política compartida, pues a estas alturas parecía una cuestión bastante resuelta ${ }^{3}$. Sino más bien de mensurar la circulación de esos afectos, que habrían de explicitar la intensidad de la sintonía de la tan pretendida integración política. Para llegar finalmente a validar la segunda variable ${ }^{4}$, concluyendo que «la mayor felicidad de una Monarquía estriva en el amor que los vassallos tienen a su Rey» ${ }^{5}$, puesto que los súbditos le habían de amar "como a bienhechor», ya que éste debía "guardar las horas de sus vasallos», teniendo siempre bien dispuesto un «mirar caricioso». Siendo, entonces, esta vigilancia amorosa sobre la que se componía el medio ajustado y virtuoso de gobierno, ya que el pueblo «ni puede llevar toda servidumbre, ni es bien darle toda la libertad», y todo ello a resultas de la convicción que la Monarquía era el régimen, en el cual el rendimiento de los vasallos se producía de forma más libre ${ }^{6}$. Así pues, de un modo abreviado pero resolutivo se ofrecía, concitado soterradamente sobre la figura del Pastor Bonus ${ }^{7}$, un entendimiento de lo político, que consistía sucintamente en «mirar a un mismo fin, que es el bien público»8.

Con todo, este capítulo de la imaginaria vigilante del pastor sobre su grey no se daba por concluido, sino que durante la segunda mitad del siglo XVII este pasto-

1 CASTRO, A., Conclusiones políticas del Príncipe y sus virtudes, Madrid, 1638, Biblioteca Nacional de España (BNE), Salón General, 3/3357.

2 BODEI, R., Ordo amoris: conflictos terrenos y felicidad celeste, Cuatro ediciones, Madrid, 1998.

3 FERNADEZ ALBALADEJO, P., «Unión de almas, autonomía de cuerpos: Sobre los lenguajes de unión en la Monarquía Católica, 1590-1630», en GARCIA HURTADO, M. R., (Coord.), Modernitas: estudios en honor del Profesor Baudilio Barreiro Mallón, A Coruña, Universidade da Coruña, 2008, pp. 111120.

4 Sobre la disyuntiva amor o temor: BERMEJO CABRERO, J. L., «Amor y temor al rey. Evolución histórica de un tópico político», Revista de Estudios Políticos, 172, 1973, pp. 107-128.

5 CASTRO, op. cit., p. 8.

6 Ibidem, p. 9.

7 Sobre este concepto FOUCAULT, M., Seguridad, Territorio, Población. Curso del College de France 1977-1978, Madrid, Akal, 2008; para su discusión hermenéutica SERRANO GONZALEZ, A., «Poder sub specie egis y poder pastoral», en MAIZ, M. (Comp.), Discurso, poder, sujeto. Lecturas sobre $M$. Foucault, 1987, pp. 115-135; para su aplicación en el pensamiento político habido en la Monarquía Católica en el siglo XVII, FERNANDEZ ALBALADEJO, P., «El pensamiento político: perfil de una "política" propia», en su Materia de España. Cultura política e identidad en la España Moderna, Marcial Pons, Madrid, 2007, pp. 93-123; en su vertiente social VAZQUEZ GARCIA, F., «Gobernante como "buen pastor". Biopolítica en la cultura española del barroco a la ilustración», Tavira, 22, (2006), 49-69; para una perspectiva europea SENELLART, M., Les ars de gouverner. Du regimen medieval au concept de governement, Editions du Seuil, Paris, 1995.

8 CASTRO, A., op. cit. p., 15. 
ralismo político alcanzará un desarrollo de notables proporciones. Tal fue así, que la comprensión del oficio del rey-pastor, que se venía manejando a fines de la década de 1650 consideraba que «no se deriva de regir, sino de apacentar» ${ }^{9}$. Carta de naturaleza, que no distaba en demasía de la proposición primigenia ofrecida en 1612 por Juan Márquez, en su obra El Governador Christiano ${ }^{10}$. Circunstancia que denotaba no ya la continuación, sino el calado e invariabilidad en sus fundamentos más básicos de esta propuesta gubernativa.

Así pues, el año de la firma de la Paz de los Pirineos ${ }^{11}$, y sin perder de vista el bien común como máxima justificativa de la actuación del príncipe-pastor, un autor aparentemente de segunda fila, Ferrer de Valdecebro, se hizo cargo de retomar y actualizar las formas pastorales como fundamento del gobierno de la Monarquía, afirmando que de "zelo y amor se componía mejor la Tiara»" ${ }^{12}$. Aunque en estos momentos de tanta turbación y desencanto parecía necesario reafirmarse en la apoyatura ideológica, que venía sustentando a la Monarquía Católica ${ }^{13}$, aseverando taxativamente que «no hay gobierno seguro sin santidad». No obstante, desde la perspectiva pastoral que el autor manejaba, el verdadero objetivo no era la simple imitación, como podría ocurrir en cualquier otra obra perteneciente a la literatura especular ${ }^{14}$, sino la traslación de esa santidad al servicio de la dinastía, la pietas austriaca ${ }^{15}$, ya que la pretensión gubernativa se concretaba sobre la conceptualización de un binomio, que disipaba cualquier duda al respecto. Es decir, “gobernavan santos, obedecían santos" ${ }^{16}$. De modo que por esta vía se consagraba el modelo de gobierno, que se venía propugnando desde comienzos de la

9 MENDO, A., El Príncipe Perfecto y ministros ajustados: documentos políticos y morales..., Salamanca, 1657, BNE, Salón General, SR/38475. Particularmente el Documento IX, Govierne el Príncipe como Pastor y como padre, p. 51.

10 FERNANDEZ ALBALADEJO, P., op. cit., p. 106. Para una aproximación a la obra de Juan Márquez: LOPEZ DE GOICOECHEA ZABALA, J., «Genesis, estructura y fuentes de El Governador Christiano (1612) de Juan Márquez», Revista Agustiniana, vol. 39, 118, (1998), 499-556; Ibidem, «Política y religión en el pensamiento de Juan Márquez (1556-1621), Cuadernos salmantinos de filosofía, 23, (1996), pp. 275-302.

11 VALLADARES RAMIREZ, R., «El Tratado de los Pirineos una revisión historiográfica (18881989), Espacio, Tiempo y Forma, Serie IV, Historia Moderna, 2, (1989), pp. 125-138; YETANO LAGUNA, I., Relaciones entre España y Francia después de la Paz de los Pirineos (1659) hasta la Guerra de la Devolución (1667). La embajada del marques de la Fuente, Madrid, Fundación Universitaria Española, 2009. 24.

12 FERRER DE VALDECEBRO, A., La Vara Vigilante, 1659, BNE, Salón General, 2/55287, pp. 23-

13 VIEJO YHARRASSARRY, J., «El sueño de Nabucodonosor. Religión y política en la Monarquía Católica a mediados del siglo XVII», Revista de Estudios Políticos (Nueva Era), 84, abril-junio, (1994), pp. 145-163.

14 GALINO CARRILLO, Ma․ A., Los tratados sobre educación de Príncipes (siglo XVI y XVII), Madrid, CSIC, 1948.

15 ALVAREZ-OSSORIO, A., Estudio introductorio a Baltasar Porreño, Dichos y hechos del Señor Rey Don Felipe Segundo, Madrid, Sociedad Estatal para la Conmemoración de los Centenarios de Felipe II y Carlos V, 2001, pp. IX- CXXVI; Ibidem, «Virtud coronada: Carlos II y la piedad de la Casa de Austria», en FERNANDEZ ALBALADEJO, P.; MARTINEZ MILLAN, J.; PINTO CRESPO, V. (Coords), Política, religión e inquisición en la España moderna: homenaje a Joaquín Pérez Villanueva, Madrid, Universidad Autónoma de Madrid, 1996, pp. 29-58.

16 FERRER DE VALDECEBRO, A., op. cit., p. 7. 
centuria, pues sugería la obligación del príncipe-pastor de imprimir y esculpir sobre cada uno de los miembros de la grey a su cargo, el conjunto de valores necesarios, de inexcusable matriz confesional católica, para obtener el bien común en su doble vertiente, espiritual y temporal. Aunque esta cita, tomada así de forma aséptica, pueda parecer que nos informe primariamente de la búsqueda de una obediencia fundada en la santidad, que sin dejar de ser cierto, lo que realmente estaba en juego era la aplicación de una de las máximas del pastoralismo ${ }^{17}$. Sería, por tanto, la consecución de la homogeneidad y uniformidad político-social ${ }^{18}$ a través de la constante intrusión del pastor en cada una de las esferas del individuo, con la pretensión de modelar su carácter, entendido éste en sentido clásico, cuyo esquema, ya preestablecido, habría de ser invariablemente el del propio pastor. Convirtiéndose en hegemónico el entendimiento de éste. Toda una declaración de intenciones. Sin embargo, habrá que esperar a 1682 para que esta máxima deje de estar implícita y se explicite, como parece recoger Núñez de Cepeda en el encabezamiento de la empresa XXV, «Donec Formentur» ${ }^{19}$, contenida en su obra ldea de El Buen Pastor ${ }^{20}$, que el propio autor explica brevemente: «Hasta formar, con el cincel de la enseñanza, en cada súbdito, una imagen ajustada a los preceptos del Salvador».

Además, y muy significativamente en la pretensión de argumentar a favor de tal ejercicio amoroso, configurado a partir del señalado binomio, se establecía una sustancial diferencia entre buen gobierno y tiranía, la cual «alcanza lo corporal, pero no llega a lo espiritual. No aflige sino lo material y dexa libre lo espiritual». Certificando que la tiranía por «acción injusta» era exclusivamente «opresión corporal», cuyo reverso contenía la viabilidad de la ingerencia pastoral ${ }^{21}$. Por tanto, una intromisión que se catalogaba positiva.

Entonces, una vez fijado el basamento, y obtenida la cohesión política gracias a la absorción de dicha santidad por parte de cada uno de los miembros de la grey, la conservación del sujeto político se reubicaba, descendiendo a la civitas terrena, y cifrándose en la obediencia al superior. Es decir, al «Príncipe Padre, Pastor y Tutor», ya que «un buen súbdito, con ciega ignorancia se haze, si obedece» ${ }^{22}$. Ahora, y sin abandonar el carácter intrusivo del pastoralismo, se potenciaba otra subordinación más naturalista, pero tan amorosa, preceptiva y benéfica como la

\footnotetext{
17 Por extenso FOUCAULT, M., Seguridad, territorio, población: curso del Collège de France (19781979), Madrid, Akal, 2008.

18 CONTRERAS CONTREARAS, J., «Procesos culturales hegemónicos: De religión y religiosidad en la España del Antiguo Régimen», Historia Social, 35, (1999), pp. 3-22.

19 Para un análisis emblemático de la misma, GARCIA MAHIQUES, R., Empresas Sacras de Núñez de Cepeda, 1988, pp. 109-112.

20 NUÑEZ DE CEPEDA, F., Idea de El Buen Pastor copiado por SS. Doctores, Representada en Empresas Sacras; con avisos espirituales, Morales, Políticos y Económicos para el Gobierno de un Príncipe Eclesiástico, Lyon, 1682, BNE, Salón General, 2/35765.

21 FUERTES Y BIOTA, A., Vida de Moysen: Parte Primera. Glosada con Sentencias y Aforismos Políticos, 1657, Bruselas, BNE, Salón General, 3/19804, pp. 25-26.

${ }^{22}$ FERRER DE VALDECEBRO, A., op. cit., p. 36.
} 
anterior, al estar encaminada perennemente a «asegurar por temporal obediencia, principado eterno» ${ }^{23}$. Lográndose al mismo tiempo la comunión entre súbdito y soberano, gracias al ejercicio de la parresía ${ }^{24}$ apostólica, consustancial a todo buen pastor en relación a sus obligaciones evangélicas. Ignorancia que será subsanada, por tanto, con la enseñanza personalizada y particularizada del maestro, como apuntaba Núñez de Cepeda, que exige obediencia para la comprensión e interiorización de la verdad. Interiorización que se convertiría en una virtud confesionalizada $^{25}$, cuyos requisitos tornarían igualmente, ya que «es triunfo el rendimiento que se hace a la virtud», actualizándose así la concepción tomista ${ }^{26}$. Además, el tratamiento de esta verdad por parte del Buen Pastor, que ejercía de superior, se reducía a la «obligación de hablar y publicarla»²7, circunstancia que por la «unción amorosa de la corrección», débito a su vez de la obediencia, explicita en este punto la adopción del status de parresiastés, de marcado carácter teológico ${ }^{28}$, cuya omnipresencia invadía todo el espacio político de la comunidad. Convirtiéndole, todo ello, en el único capacitado para ejercer de guía, puesto que «es la ausencia del Superior, insolencia del Súbdito, gobierno sin cabeza, ovejas sin pastor, pasajero sin guía, Discípulo sin Maestro „29. Para apuntalar tales consideraciones sobre los fundamentos del gobierno con base en una vita contemplativa, emanada de la educación, que engendra la disciplina ${ }^{30}$, Fuertes y Biota seguidamente argumentaba que «el Maestro si quiere, tiene todo lo que ha menester, porque con saber y querer se haze todo" ${ }^{31}$.

A todo lo cual se añadiría la demanda de la verdad por parte del súbdito, lo que implicaba acercarse al Padre, teniendo por reverso tangible y positivo el deseo del conocimiento de la vera religio. Aproximación, que por otra parte suponía la incor-

23 Ibidem, p. 12.

24 FOUCAULT, M., Discurso y verdad en la antigua Grecia, Barcelona, Paidós, 2004, especialmente aquellas dedicadas al trato personalizado enfocado a la educación, pp. 144-152.

25 Para una aproximación a la misma el siempre útil FERNANDEZ SANTAMARIA, J. A., Razón de Estado y política en el pensamiento español del Barroco (1595-1640), Madrid, Centro de Estudios Constitucionales, 1986; IÑURRITEGUI RODRIGUEZ, J. M., La Gracia y la República. El lenguaje de la teología católica y el Príncipe Cristiano de Pedro de Ribadeneira, Madrid, UNED, 1998.

26 VARA MARTIN, J., De la obediencia a la unidad. Estudio sobre el orden político en el pensamiento de santo Tomas de Aquino, Madrid, CEU Ediciones, 2008, pp. 109-128

27 FERRER DE VALDECEBRO, A., op. cit., p. 198.

28 Obsérvese la correspondencia a su vez con Efesios 3,12: «En quien tenemos la franca seguridad de acercarnos a El confiadamente por la fe»; 2 Corintios 3,12: «Teniendo, pues, tal esperanza, procedemos con plena libertad»; 2 Corintios 7,4: «Tengo mucha confianza con vosotros; tengo en vosotros grande motivo de gloria, estoy lleno de consuelo, reboso de gozo en todas nuestras tribulaciones»; Hechos 4,13: «Viendo la franqueza de Pedro y Juan y considerando que eran hombres sin letras y plebeyos, se maravillaban, pues los habían conocido de estaban con Jesús»; Hechos 4, 31: «Después de haber orado, tembló el lugar en que estaban reunidos, y todos fueron llenos del Espíritu Santo y hablaban la palabra de Dios con libertad»; Hechos 28,31: «Predicando el reino de Dios y enseñando con toda libertad y sin obstáculo lo tocante al Señor Jesucristo». Sigo la edición a cargo de NACAR FUSTER, E., y COLUNGA CUETO, A., Nuevo Testamento. Versión directa del texto original griego, Madrid, Biblioteca de Autores Cristianos, 1975.

29 FERRER DE VALDECEBRO, A., op. cit., pp. 73-74.

30 FOUCAULT, M., Vigilar y castigar: nacimiento de la prisión, Madrid, Siglo Veintiuno, 2008.

31 FUERTES Y BIOTA, A., op. cit., p. 25. 
poración de la Economía ${ }^{32}$ de raigambre clásico, produciéndose la asunción de sus prescripciones, concitadas en la cabeza del corpus misticum politicum, y con ello la exclusión de la política ${ }^{33}$. Todo lo cual, a resultas de que los súbditos «han de alterar el animo del Rey, que aunque sea Padre, ha de sentir que el hijo aliente donde el manda» ${ }^{34}$. Idea de cierta ambigüedad esta última, ya que el recurso a este "aliente», proporciona un doble entendimiento, que al tiempo completa y clausura el argumento del discurso pastoral. Es decir, en una primera lectura podría apreciarse que el poder económico, que le corresponde al príncipe temporal no ha de ser asfixiante, aunque le capacita a imponer su autoridad y llevar su mandato hasta el límite. Mientras que en una segunda lectura, por el contrario, también puede ser pensado como el acto del hijo obediente que reclama y acapara sobre sí la dirección del padre, lo que podía ser entendido como una forma de autodisciplinarse. De modo que a través de este sutil sintagma, que aparentemente excluía el amor como dispositivo disciplinante, incardinaba el carácter cuantitativo y cualitativo consustancial al poder pastoral ${ }^{35}$. Así pues, se trataba en definitiva del acrecentamiento de la autonomía ${ }^{36}$ de la autoridad del príncipe temporal, en la que la suprema potestas no incurría en un excessus potestatis. Por tanto, no era una vacua disposición del poder y autoridad, ni mucho menos un «mixto imperio ${ }^{37}$, ya que nadie podía objetar al ser toda decisión del Príncipe Padre y Pastor un «decreto sin replica», pues «no era la resolución acto de Justicia, sino de Gobierno. Era acción de estado, y se había de ejecutar», aunque el dictamen fuese riguro$\mathrm{so}^{38}$. Asomando, así, de forma resuelta y decidida una soberanía pastoral, sobre la que se venía apoyando y justificando, primero la cosmovisión confesional de la Monarquía Católica, y luego ese pretendido mayor grado de operatividad ${ }^{39}$, nacido de la obediencia filial y la disciplina amorosa.

32 Para la aplicación de este concepto en la Edad Moderna FRIGO, D., II Padre de famiglia. Governo della Casa e governo civil nella tradizione dellNeconomica tra cinque e seicento, Roma, 1985; ATIENZA HERNÁNDEZ, I. «Pater familias, señor y patrón: oeconómica, clientelismo y patronato en el Antiguo Régimen", en PASTOR, R., Relaciones de poder, de producción y de parentesco en la Edad Media y Moderna, 1990, pp. 411-458.

33 VIEJO YHARRASSARRY, J., «Ausencia de política: ordenación interna y proyecto europeo en la Monarquía Católica de mediados del siglo XVII», Actas de la IV Reunión Científica de la Asociación Española de Historia Moderna. Monarquía, Imperio y pueblos en la España Moderna, Vol. 1, Alicante, 1997, pp. 615-630; para un acercamiento a la conceptualización que se realizaba de la analogía corporativa: BERTELLI, S., El corpo del re: sacralità del potere nell Europa medievale e moderna, 1995.

34 FUERTES Y BIOTA, A., op. cit., p. 138.

35 Para un análisis del componente cuantitativo y cualitativo del poder pastoral contextualizado en el pensamiento moderno: HYNDESS, B., Disertaciones sobre el poder. De Hobbes a Foucault, Madrid, Talasa Ediciones, 1997.

${ }^{36}$ ASCH, R. G., y DUCHHARD, H. (Eds.), El Absolutismo, ¿un mito? Revisión de un concepto historiográfico clave, Barcelona, Idea Books, 2000.

${ }_{37}$ RUBIÉS, J. P., «La idea del gobierno mixto y su significado en la crisis de la monarquía Hispánica», Historia Social, 24, (1996), pp. 195-208.

38 FUERTES Y BIOTA, A., op. cit., pp. 23, 24 y 39.

39 FERNANDEZ ALBALADEJO, P., «El pensamiento político: perfil de una "política”...», pp. 118-123; Ibidem, "La Crisis de la Monarquía. El siglo XVII», Historia de España. Joseph Fontana y Ramón Villares (dirs.), Vol. 4, Madrid, Critica/Marcial Pons, 2009, pp. 375 y ss.; para posteriores aplicaciones IÑURRITEGUI RODRIGUEZ, J. M., Gobernar la ocasión. Preludio de la Nueva Planta, Madrid, Centro de Estudios Políticos y Constitucionales, 2008. 
Sin embargo, si retomamos el fundamento primero sobre el que se apoyaba el tratamiento, que aplica el Buen pastor a cada una de las ovejas a su cargo, a saber, «un mismo y único método no puede aplicarse a todos los hombres, porque no todos están regidos por una igual naturaleza de carácter. Con frecuencia son nocivos para algunos los procedimientos de otros" ${ }^{40}$. Máxima que se complementaría con el recurso a la costumbre, ya que «ninguna entre las leies humanas más poderosa y suprema que la costumbre», que tiene como «regalía ser árbitro de las leies, pues con su autoridad las interpreta, las modifica, las anula talvez, las forma y las introduce», pues "es un imperio de la raçón, que reside en el consentimiento general de los ánimos ${ }^{41}$. Expediente que sugería el apego al mantenimiento de los distintos estilos de gobierno. Idea que vendría a revitalizar y consolidar la estructura compuesta de la Monarquía Católica, lo que se traducía en el bloqueo de la homogeneización, contenida en la figura pastoral, pero no de la cohesión y del surgimiento de un orden superior, causante de la filial obediencia. Contradicción, que explicitaba la pretensión de compatibilizar las limitaciones estructurales con la vindicación de una mayor operatividad en la esfera de lo político.

Conjunto de elementos, pues, que se completaban con la ejecución de una traslatio imperii, extraída de la siempre presente tesis del poder descendente, por la que el príncipe temporal se convertía en el vicario de Cristo, pues «Moisés humilde en el valle, baxó con nuevo esplendor del monte; le sirvió para hazer más rendida la obediencia en los Hebreos». De modo, que «al pueblo se le dio necesidad de obedecer, y de tener por Vice Dios temporal en la tierra al Rey: fue puesto en condición de reconocer Vassalaje, y de no apartarse de la obediencia al Rey ${ }^{42}$. A partir de todo lo cual, se imponía al conjunto de los agregados el ejercicio de una vita contemplativa ${ }^{43}$, ya que a través tan solo de la contemplación se instruía en la verdad, pero siempre penetrado por la caritas ${ }^{44}$, ya postulado por San Agustin ${ }^{45}$. Coordenadas que clausuraban la cosmovisión vigente de matriz confesional, que se definía a partir de la asunción de una monarquía en Ecclesia como forma de gobierno ${ }^{46}$.

40 HOlgado RAMIREZ, A., y RICO PAVES, J. (Eds.), Gregorio Magno. La Regla Pastoral, Madrid, Ciudad Nueva, 1993.

41 NÚÑEZ DE CEPEDA, F., op. cit., pp. 146-147.

42 FUERTES Y BIOTA, op. cit., p. 129.

43 FERNANDEZ ALBALADEJO, P.,» «Católicos antes que ciudadanos: gestación de una política española en los comienzos de la Edad Moderna», en FORTEA PÉREZ, J. M. (Coord.), Imágenes de la diversidad: el mundo urbano en la Corona de Castilla siglos XVI-XVIII, 1997, pp. 103-127.

44 CLAVERO, B., Antidora. Antropología católica de la economía moderna, Milán, Giuffrè, 1991, pp.61-65; TOMAR ROMERO, F., «Desde el amor: caridad y solidaridad», en Cuadernos de pensamiento, 18, (2007), pp. 85-105.

45 LAZCANO, R., «Notas sobre la obediencia en San Agustín», Revista Agustiniana, Vol. 25, 76-77, (1984), pp. 219-236.

46 IÑURRITEGUI RODRÍGUEZ, J. M., La Gracia y la República. El lenguaje de la teología católica y el Príncipe Cristiano de Pedro de Ribadeneira, Madrid, UNED, 1998, p. 301-355. 
Parecía suficiente, por tanto, a fines de la década de 1650 el dispositivo de gobierno basado en la "disciplina Eclesiástica» ${ }^{47}$, para obtener una «juventud disciplinada», al entenderse que ésta era la raíz más fecunda sobre la que sostener el provecho de toda la República ${ }^{48}$. No obstante, la concepción de la disciplina que se propugnaba como solución al problema de la operatividad de "un imperio tan desparramado", aunque partiendo de posiciones naturalistas, se acercaba más a la analogía mecanicista, y más concretamente a los engranajes ajustados de un reloj mecánico ${ }^{49}$. Metáfora que se relacionaba en el Barroco hispano con la obediencia automática, instintiva e irreflexiva, y no condicionada por los recursos a una traslatio imperii inconclusa, como sucedía en otros reinos peninsulares ${ }^{50}$. Sin embargo, avanzado el siglo y en un momento tan complicado como 1684 , se trascendían tales consideraciones y se pasaba a certificar que la comunidad política "se conservará en la disciplina de la guerra, y en la felicidad de la paz constante ${ }^{51}$. Cobraba, así, sentido la organización de una sociedad de cuño castrense y marcial ${ }^{52}$, en la que el mandato del oficial de rango superior no sería discutido, sino acatado por el agregado al rebaño que comanda el Buen Pastor como si de un autómata se tratase. Sin olvidar, que «lo sagrado de la púrpura sublima» al príncipe temporal «a esfera superior». Distinción que compromete al príncipe a diferenciarse con perfección virtuosa. Por tanto, «cualquiera acción, que degenere de esta obligación forçosa, es indignidad de la Magestad excelsa; borrón osbcuro de las resplandores de la Corona" ${ }^{53}$. Así pues, a mediados de la década de 1670 se profundiza en este sentido de la mano de Juan Vela, juzgando que profesar la compañía del Buen Pastor «es seguir el camino de la verdad, y de la vida", mientras que «apartarse dél, es descaminarse, para tropezar en la mentira y despeñarse en la muerte». Por tanto, el Buen Pastor es el guía de la comunidad, que les ha de conducir por «senda segura», a imitación de Cristo que cumplió con sus obligaciones pastorales «hasta rendir la vida por el bien universal de sus vassallos $"{ }^{54}$. Verdad y vida constituían, a tales efectos, un binomio indisoluble. Tal es así, que Vela con prontitud identifica como principal obligación del Buen Pastor el «atender a la conservación de sus vassallos». Por ello, el recurso del sacrificio vital del Buen Pastor contribuiría a fortalecer la

47 PALOMO, F., «"Disciplina christiana”. Apuntes historiográficos en torno a la disciplina y el disciplinamiento social como categorías de la historia religiosa de la alta Edad Moderna», Cuadernos de Historia Moderna, 18, (1997), pp. 119-135.

48 FERRER DE VALDECEBRO, A., op. cit., p. 207.

49 Para las posibles aplicaciones de esta metáfora durante el Barroco hispano: GARCIA GONZALEZ, J. M., Metáforas del poder, Madrid, Alianza Editorial, 1998, pp. 156-176.

50 FERNANDEZ ALBALADEJO, P., «Lex Regia Aragonensium: monarquía compuesta e identidad de reinos en el reinado de Felipe II», en su Materia de España. Cultura política e identidad en la España Moderna, Madrid, Marcial Pons, 2007, pp. 65-91.

51 CORTES OSORIO, J., Constancia de la Fee y aliento de la nobleza española, Madrid, 1684, BNE, Salón General, 3/20363, p. 18.

52 HYNDESS, B., op. cit., p. 114

53 VELA, J., Política Real y Sagrada discurrida por la vida de Jesu Christo, para el gobierno de los príncipes, elección y acierto de sus ministros, 1675, BNE, Salón General, 1/22941, p. 1.

54 VELA, J., op. cit., p. 4. 
conceptualización de la protección, que debía ofrecer el príncipe, al tiempo que en un momento tan precario internacionalmente habría de alentar la colaboración interprovincial. Por ello mismo, la conformidad propia de la unidad, desde esta óptica, sería consecuencia de la puntualidad con la que el monarca debía acudir en auxilio de sus súbditos, favoreciendo con ello el proceso de consolidación y acrecentamiento de la autoridad regia ${ }^{55}$. Pues, "Consejo es de Christo" que «la vara de gobierno siempre debe estar armada de vigilancia» 56 , con la que asegurar su conservación, ya que reinar consistía en la asunción perpetua de cuidar, defender a los súbditos en los peligros y socorrerlos en las necesidades. En definitiva, «liberarlos de la voracidad de los lobos» ${ }^{57}$. Cuestión que conecta con la ineludible obligación del Buen Pastor de proporcionar el debido sustento a sus ovejas, es decir, «no dar lugar a que perezcan de hambre». Con todo, Vela no se conforma y profundiza aún más en esta cuestión, al considerar que para asegurar el bienestar de los súbditos no basta con conducir el rebaño hacia pastos saludables. Es decir, la política que ha de llevar a la consecución exitosa de sus funciones ha de consistir, retomando la metáfora pastoral, en que el Buen Pastor "trasquile a sus ovejas, no las desuelle, que beba su leche, no su sangre». Elemento central que habilita y articula el poder pastoral, o cuando menos, la acción del Buen Pastor al frente del rebaño, pues tomando de nuevo como ejemplo a Cristo afirma, que «toda su vida fue un amor encendido en la común utilidad», al tiempo que deseó que los hombres «le rindiesen vasallage por amante que por omnipotente»58. En definitiva, el príncipe debía tener una participación activa en la consecución del bien común a través del amor ${ }^{59}$, siendo su mejor expresión la Orden del Toisón de Oro, afirmándose que «esse tusón de oro es indicio de la nobleça de su caridad, que le obliga no solo a tener la en el corazón ocultas, sino manifiesta en el exterior de todas sus obras socorriendo como Padre amoroso con entrañas de piedad y conmiseración las necesidades»60. Por tanto, el toisón de oro, siendo la máxima distinción de la elevada calidad de los hombres, sería a su vez la ejemplificación de aquella virtud que se precisa para la dirección exitosa de la comunidad.

De modo, que incluso en este punto aparentemente tan distante de las cuestiones tratadas hasta ahora, se sublimaba el amor como dispositivo por el cual se obtenía el bien común y la unidad. Presupuesto que tendrá continuidad de nuevo

55 Idea que se manejaba ya en durante el valimiento del Conde-duque: ESTEBAN ESTRINGANA, A., «El consenso como fundamento de la cohesión monárquica. La operatividad política del binomio protección-defensa en los Países Bajos del siglo XVII», en GUILLAMÓN, F. J., y RUIZ IBÁÑ̃̃Z, J. J. (Eds.), Lo conflictivo y lo consensual en Castilla. Sociedad y poder político (1521-1715), Universidad de Murcia, Murcia, 2001, pp. 325-376.

56 NÚÑEZ DE CEPEDA, op. cit., p. 160.

57 VELA, J., op. cit., p. 8.

58 Ibidem, p. 40.

59 CARDIM, P., «Memoria comunitaria y dinámica constitucional en Portugal», en FERNANDEZ ALBALADEJO, P., Los Borbones: dinastía y memoria de nación en la España del siglo XVIII, Madrid, Marcial Pons, 2002, p. 125.

60 NÚÑEZ DE CEPEDA, F., op. cit., p. 381. 
en Ferrer de Valdecebro ${ }^{61}$, afirmando que "el amor es el lazo que une con dulce vínculo el cuerpo del Reyno con su cabeza el Rey» ${ }^{62}$. Por lo que su ausencia se observaba como una desviación equiparable a la carencia de justicia, que degeneraría invariablemente en la Discordia. No obstante, la relación de la justicia con el amor no se reducía a una mera equiparación, sino que el vigor del amor era de mayor envergadura, concluyendo que «la justicia es un amor, que solo sirve al amado» ${ }^{63}$. Estableciéndose una correlación basada en el amor, que acarreaba a la justicia y ésta a la paz. Correlación que pivotada inextricablemente sobre la religión, puesto que «la paz temporal, y bienaventurança del Príncipe no se puede conseguir, si el Pueblo no vive ajustado". Es decir, obediencia y disciplina fundada en la superior condición del Príncipe, siendo entendido como «una ley que habla», a consecuencia de una potencia virtuosa fruto del «amor que la Religión engendra»64. Por tanto, el punto de partida seguía siendo la Religión, cuyo referente era el Amor Dei, ya que no actuar en pro de los miembros de la comunidad sería «lo mismo que cerrar la puerta a la piedad» ${ }^{65}$. Para concluir concibiendo, que la ley «haze suave la obediencia con medio proporcionado, entre la servidumbre y la libertad ${ }^{66}$. Una similitud considerable, recordemos, con el efecto que provocaba la Monarquía. Por lo tanto, ley y monarquía como medios ajustados y proporcionados. En esencia, un binomio sin jerarquía por la igual condición de sus componentes, según este planteamiento, pues el amor, ya caritas, por tanto confesionalizado, pasaba a ser el dispositivo cualificado que atravesaba este entendimiento de lo político, habilitando tal rectitud. Es decir, el seguimiento de la "senda segura» que el Buen Pastor conoce y enseña, ya que la caridad pasaba a ser «la perfección de la virtud», y «el círculo con que esta virtud se corona como reyna» ${ }^{67}$. Se trataba de una ordenación amorosa producto de una creación amorosa. Conceptualización, ésta la del Barroco hispano ${ }^{68}$, basada en la circulación de esos afectos amorosos jerarquizados, que explicitaban la no dominación ${ }^{69}$, así como el sometimiento a una conducción virtuosa. Sencillamente porque la Providencia «sola-

61 FERRER DE VALDECEBRO, A., El Cetro con ojos, Madrid, 1678, BNE, Salón General, 3/25275, pp. 2-6.

62 Cuestión que ya ha sido resaltada por VIEJO YHARRASSARRY, J., «"El amor propio en el infierno". Pasiones y gobierno en la Monarquía Hispánica", en Fénix de España. Modernidad y cultura propia en la España del siglo XVIII (1737-1766), Madrid, Marcial Pons, 2006, pp. 73-92.

63 FERRER DE VALDECEBRO, A., op. cit., pp. 12-13; SERRANO GONZALEZ, A., «La senda amorosa del Derecho. Amor y ivstitia en el discurso jurídico moderno", en PETIT, C., Pasiones del jurista. Amor, memoria, melancolía, imaginación, Madrid, Centro de Estudios Constitucionales, 1997, pp. 24-73; HESPANHA, A. M., La gracia del derecho: economía de la cultura en la Edad Moderna, Madrid, Centro de Estudios Constitucionales, 1993.

${ }^{64}$ FERRER DE VALDECEBRO, A., op. cit., pp. 184-185.

65 VELA, J., op. cit., p. 27.

66 FERRER DE VALDECEBRO, A., La vara..., p. 96-97.

67 NUÑEZ DE CEPEDA, F., op. cit., p. 206.

68 Para un planteamiento novedoso; RODRIGUEZ DE LA FLOR, F., La Península Metafísica. Arte, literatura y pensamiento en la España de la Contrarreforma, Madrid, Biblioteca Nueva, 1999; Ibidem, Barroco. Ideología y representación en el mundo hispánico (1580-1680), Madrid, Cátedra, 2002.

${ }_{69}$ Para un primer acercamiento a tal concepto de índole republicano: PETTIT, P., Republicanismo. Una teoría sobre la libertad y el gobierno, Barcelona, Paidós Ibérica, 1999, especialmente cap. II y III. 
mente a los hombres, y a los Ángeles, como a las Republicas nobles, les guardó su libertad, poniéndoles por tributo la obediencia, y el reconocimiento de su grandeza» ${ }^{70}$. Actualizándose en este punto la concepción tomista, según la cual «la vida social no es posible si no hay alguien que la dirija al bien común » ${ }^{71}$. Lugares en los que cobraba especial relevancia la Economía de raigambre clásica. En definitiva, verdad y vida, que exigían virtud, la cual tornaba en obediencia y disciplina en torno a un «Padre amoroso».

El siguiente paso, por tanto, sería reconocer al guía de la comunidad, estableciéndose las oportunas conexiones con la Providencia, al concebir a los miembros de la comunidad, invariablemente católicos, como peregrinos que transitan por el mundo hacia la salvación ${ }^{72}$. El reconocimiento recaerá en el máximo ejemplo de Buen Pastor, Moisés, que designado por Dios para tan alto oficio

«ya perfecto, sus pasiones en paz, millares de hombres le admitieron como por su caudillo, haciéndole árbitro».

Insistir en que «admitir» no supone elegir, pero por el contrario tampoco supone imposición. Por lo tanto, una suerte de no dominación, potenciándose una aceptación tácita, cuya clave estribaba en el consensus populi acerca del príncipepastor, el cual asumía la condición de ley que habría de conducirlos hacia el bien común. Además, este consensus populi, propio de la neoescolástica castellana, podría estar inspirada en la expresión de Cicerón iuris consensus ${ }^{73}$, la cual normalmente ha sido interpretado en clave contractualista (consenso en cuanto o sobre el derecho), por lo que la comunidad política se establecería por la libre voluntad de quienes la forman. Sin embargo, iuris consensus no se ciñe al arreglo de todos o de la mayoría respecto de una ley común, sino más bien «la armonía del derecho", es decir, el acuerdo entre las diversas normas jurídicas que de modo natural y por tanto inevitable hace nacer la comunidad política ${ }^{74}$, pero para nosotros entendida en clave monárquica. Como revela la tan asidua metáfora del instrumento musical, el consenso consiste en que todos se sometan a la misma partitu$\mathrm{ra}^{75}$, al mismo ius. Así pues, el propio Núñez de Cepeda afirma que:

«Es la República un sarao de quenta bien concertado, cuio primor consiste en que guardando cada uno de los ciudadanos proporción y su puesto se muevan to-

70 CORTES OSORIO, J., op. cit., p. 27.

71 Suma Teológica, tomo III, I, q. 96, a. 4.

72 VELA, J., op. cit., p. 55: «Es acaso porque estando [Cristo] en Cruz espectáculo lastimoso de ángeles, y de los hombres, llamará a los pasageros del mundo a que se conduelan de su padecer? (...) Condolidos todos de sus tormentos, se enternecerán las más endurecidas peñas, manifestando su amor en sus sentimientos»; IÑURRITEGUI RODRÍGUEZ, J. M., La Gracia y la República. El lenguaje político de la teología católica..., pp. 25-26.

73 CICERÓN, REP., 3,45.

74 En este punto seguimos la interpretación del profesor LOPEZ BARJA DE QUIROGA, P., Imperio legítimo. El pensamiento político en tiempos de Cicerón, Madrid, Antonio Machado Libros, 2007, p. 204.

75 CICERÓN, REP., 2, 69. 
dos el compás de la acorde música de las leyes que componen el PSalterio de diez cuerdas, o preceptos divinos con que David aconsejava al pueblo acompañasse sus voces ${ }^{76}$.

En este fragmento podemos ver como la comunidad es una reunión casi festiva bien concertada, en la que todo individuo atento a guardar su status y rol, ha de desenvolverse en dicha comunidad conforme al dictado armonioso de unas normas, que lógicamente no podrían ser sino los Diez Mandamientos, que el rey David en su papel de Buen Pastor logra amorosamente que el pueblo las respete, las asuma y las haga suyas en cada una de sus acciones. En definitiva, con esta metáfora musical se expresaba la antes mencionada «armonía del derecho» en forma de aceptación y respeto, que el propio Núñez de Cepeda imprime el énfasis necesario, afirmando que «en cuya observancia se debe fundar la paz verdadera ${ }^{77}$. Asimismo, si tenemos en cuenta otra de las máximas del pastoralismo ${ }^{78}$, según la cual el rebaño existe, primero, en y a través de la presencia del pastor, y a continuación, gracias a la actividad del mismo, pues faltando éste es posible que el rebaño se disuelva en una multitud de individuos inconexa. Entonces, podríamos considerar que la tal armonía del derecho se concretaba en la figura del Buen Pastor, expresión de la unidad, reapareciendo de nuevo la Economía de raigambre clásico, ya que «la familia domestica» se caracterizaba invariablemente por su «inseparable unión " ${ }^{79}$. De modo que unos y otros se reubicaban, quedando concitados en el Buen Pastor, encargado de guiar hacia el bien común. Por tanto, el Buen Pastor era un bien en sí mismo.

Además, en ciertas ocasiones se establecía igualmente la asimilación entre bien común y bien del pueblo, facilitada en parte por la semejanza con la res familiaris, que puede ser entendida como patrimonio familiar. De modo que el bien del pueblo puede entenderse como el patrimonio del pueblo. En este punto surge con fuerza una visión material y tangible de todas estas abstracciones, pudiéndose leer en clave económica y pensar en una hacienda, una suerte de tesoro del común.

No obstante, a diferencia de otras ocasiones en las que se concibe engañosa la ecuación res publica = estado, que haría pensar la res populi como una referencia, vaga y ambigua, de todo aquello que pueda ser provechoso para la comunidad $^{80}$. Es factible pensar, entonces, que una vez que el pensamiento clásico, ya fuese en su versión aristotélica o ciceroniana, quedase atravesado y sujeto a los presupuestos del Cristianismo, esta ecuación pasaba a ser una realidad, pues las riquezas terrenas «después de que son sudor de los pobres, fueron ganadas con

${ }^{76}$ NÚÑEZ DE CEPEDA, F., op. cit., pp. 617-618.

77 Ibidem, p. 474.

78 Remitimos nuevamente por extenso a FOUCAULT, M., Seguridad, Territorio, Población...

79 GUTIERREZ DE LOS RIOS, F., El hombre practico o discursos varios sobre su conocimiento y enseñanza, Bruselas, 1686, BNE, Salón general, 3/29644, p. 203.

80 LOPEZ BARJA DE QUIROGA, P., op. cit., pp. 182-183 y ss. 
la sangre de Christo» 81 . Hay, por tanto, un principio de propiedad, que al tiempo asegura la independencia, la no-dominación, la no explotación de los menesterosos y desvalidos. Una especie de liberación, que no debe ser confundida con la libertas clásica, cuyo significado sería una especie de capacidad para la participación política. En cambio, para Núñez de Cepeda las palabras de Cristo fueron bastante claras al respecto: «esto, el caudal de mis tesoros, que a costa de la vida gané para los pobres en la batalla sangrienta de el calvario» ha de servir para poner fin al clamor de los desvalidos, que

«dicen entre quejas y suspiros: Ai de vosotros que quitáis de nuestras necesidades, lo que consumís en la vanidad de vuestros excesos! Vuestra codicia es raíz de dos daños intolerables: porque vosotros morís ahogados en el humo de vanos desperdicios y a nosotros nos despojáis de sustento y vida»82.

El objetivo de toda esta parábola se circunscribía a introducir soterradamente, que este entendimiento «entroniza a la salud pública»83. Por ello, aunque todos los bienes del Buen Pastor, en esta ocasión presentado como prelado, pues los representantes de la Casa de Austria no tuvieron reparos en postular su voluntad de cultivar la imagen de rex et sacerdos ${ }^{84}$, los recibiese de la mano de Dios, y Núñez de Cepeda llegue a afirmar que el prelado disfrute de un mayorazgo ${ }^{85}$ sobre las rentas. Retoma más adelante esta afirmación y asegura que éstas antes fueron concedidas a las «entrañas de Christo que son los pobres", recriminando a los hombres su mala praxis, al consumirlas «en vanos desperdicios» como si las «huvieran heredado de sus padres». Así pues, la Providencia recuperó los bienes de la tierra para los pobres, de modo que se los otorgó primero a ellos, siendo suyos incluso antes, es decir, una suerte de devolución redentora, pero no una dádiva graciosa. Sin embargo, para que fueran distribuidos correctamente se los otorgó en forma de mayorazgo al Buen Pastor, explicitándose las conexiones $\mathrm{Ci}$ vitas Dei y civitas terrena, garantizando así su correcta restitución a través de la caridad cristiana ${ }^{86}$, que debía asegurar un mínimo de salud pública, sujeta a la justicia distributiva y conmutativa ${ }^{87}$ ordenadora de la jerarquía social. Dibujándose en este sentido otra traslatio imperii. Por tanto, se culminaba la idea del rey-adminis-

${ }^{81}$ NÚÑEZ DE CEPEDA, F., op. cit., p.346.

82 Ibidem, pp. 345 y 345.

83 Ibidem, p. 86.

${ }^{84}$ FERNANDEZ ALBALADEJO, P., «El pensamiento político: perfil de una "política"...», pp. 103.

85 NUÑNEZ DE CEPEDA, F., op. cit., p. 251; CLAVERO, B., Mayorazgo. Propiedad feudal en Castilla, 1369-1836, Madrid, Siglo XXI, 1989.

$86 \mathrm{Ibidem}, \mathrm{p}$. 393. Igualmente, desde la óptica que venimos manejando, también consideramos acertadas las afirmaciones, por las que el estado racionalmente constituido, alumbrado más allá de la época que nos ocupa, se articularía sobre una obligación moral compartida, cuyo origen se encontraba no en una prudencia neoestoica, sino en una piedad cristiana, expresada a través de la caridad, postuladas por MODOD, P. K., El poder de los reyes. Monarquía y religión en Europa, 1580-1715, Madrid, Alianza Editorial, 2001, pp. 292 y 322 esp.

${ }_{87}$ Para el desarrollo de los planteamientos senequistas en España durante el Barroco, BLÕHER, K. A., Séneca en España. Investigaciones sobre la recepción de Séneca en España desde el siglo XIII hasta el siglo XVII, Madrid, Gredos, 1983. 
trador, que según lo trazado, al tiempo que se establecía un mayorazgo, que por intercesión divina prevista en su plan providente otorga su tutela al Buen Pastor. Sería un mayorazgo con perspectivas sociales, puesto que el poder pastoral, así planteado, aunque sirva para el acrecentamiento del poder regio a través de la eliminación de intermediarios, está impelido a garantizar el bien común con pretensiones individualizantes. En consecuencia, se está más interesado en garantizar el bienestar que la libertad de los agregados, que pasan a ser sus administrados. Concepción que se apoyaba tras el refrendo de ser una «causa justa» la búsqueda de la salus populi.

Encuadramiento que tenía su expresión ya organizada en otro dispositivo de mayor envergadura como era la «policía»88. Concepto igualmente confesionalizado ${ }^{89}$, que sucintamente se resumía en un «esplendor» del reino. Cualidad, recordemos, que formaba parte de Moisés tras su admisión. Por tanto, podría pensarse que el dispositivo policial, el objetivo último del bien común y la soberanía se superponían, mezclaban, apoyaban y se incorporaban unas a otras, cuya distinción se complicaba, a consecuencia de ser todo ello concitado en las formas pastorales extraídas de la religión.

Para la consecución de este pretendido encuadramiento, según plantea Vela, se debía recurrir primariamente, y de forma fundamental, a la «estadística», cuyo significado al respecto es bastante revelador: conocimiento de poder ${ }^{90}$. Aunque también se apelaba a otras variantes de la misma, como podía ser la «Matemática» ${ }^{91}$. De ahí que Juan Vela, autor que ofrece una visión bastante completa de lo planteado, comience afirmando que la primera acción de gobierno del príncipe temporal sea conocer su capacidad de acción. Vela, de algún modo, estaría hablando de la concepción cuantitativa del poder, por lo que resultaba ineludible averiguar con que «fuerzas» cuenta el reino. Hay, por tanto, una pretensión de conocer el estado del mismo, no solo para en el caso de tener que hacer frente a un posible enemigo, sino también para llevar a cabo una buena administración de la res familiaris, adoptando las medidas más idóneas para lograr, así, un ejercicio equilibrado y responsable, y no provocar un desbarajuste entre las pretensiones de actuar y las posibilidades de obrar ${ }^{92}$. Obviamente, Vela lo que está esbozando, de forma amplia, aparte de la identificación rey-administrador, es el diseño de un modelo de actuación estratégica, en la que se implique al conjunto del reino. Es, en este punto, donde tales planteamientos asumían la presencia de un cierto com-

88 Seguimos en este punto FOUCAULT, M., «Gubernamentalidad», en Estética, ética y hermenéutica, Vol. III, Barcelona, Paidós, 1999, pp. 175-199; PASQUINO, P., «Police spirituelle et police terrienne», en LAZZERRI, C., REYNIE, D. (Eds.), La raison d'État: politique et rationalitè, Paris, PUF, 1992, pp. 83115.

89 Para una aproximación al mismo SANTAMARIA, F., Tratado de Republica y Policía Christiana, Madrid, 1615.

90 FOUCAULT, M., op. cit., pp. 243-270.

91 FERRER DE VALDECEBRO, A., El Cetro..., pp. 47, 49, 51.

92 VELA, J., op. cit., pp. 48-49. 
ponente maquiaveliano ${ }^{93}$, al concebir la estrategia como una necesidad, aunque sujeta a la moral cristiana. En definitiva, a partir de ahora la propuesta de Maquiavelo, conceptualizada en la tan debatida razón de estado ${ }^{94}$, comenzó a perder sus connotaciones negativas, siendo penetrada por las obligaciones de la caritas y reelaborada bajo los presupuestos del pastoralismo, que propugnaba como reverso a sus exigencias de obediencia y disciplina un cierto bienestar, pasando a ser entendida de una manera bastante diferente ${ }^{95}$. Por tanto, la razón de estado a partir de ahora comenzará a ser concebida como la regla que permite asegurar la paz, que concede el bien común, cuya fijación parecía haberse producido ya a fines de la década de 1650. Concretamente de la mano de Fuertes y Biota en su obra Vida de Moysen, al codificar todo este programa gubernativo en una «razón de estado publica» ${ }^{96}$, la cual a su vez se hacía acompañar de una tangible soberanía pastoral.

93 Para las diferencias entre maquiavélico y maquiaveliano ver la reciente obra a cargo de FORTE, J. M., y LÓPEZ ÁLVARES (Eds.), Maquiavelo y España. Maquiavelismo y antimaquiavelismo en la cultura española de los siglos XVI-XVII, Madrid, Biblioteca Nueva, 2008, pp. 11-40; MARAVALL, J. A., «Maquiavelo y el maquiavelismo en España», en Estudios del pensamiento español. Siglo XVII, Madrid Cultura Hispánica, 1975, pp. 41-76; Ibidem, «La cuestión del maquiavelismo y el significado de la voz "estadista"», en Estudios del pensamiento español. Siglo XVII, Madrid, Cultura Hispánica, 1975,109-123. Para otras cuestiones ARAMAYO, R., y VILLACAÑAS, J. L. (Comps.), La herencia de Maquiavelo: modernidad y voluntad de poder, Madrid, Fondo de Cultura Económica, 1999.

94 Para una aproximación en estos momentos VIEJO YHARRASSARRY, J., «Razón de estado católica y la monarquía hispánica», Revista de Estudios políticos, 34, (1999), pp. 233-244.

95 Remitimos por extenso de nuevo a FOUCAULT, M., Seguridad, Territorio, Población...

96 FUERTES Y BIOTA, A., op. cit., pp. 16, 37. 
